\title{
Role of lumican in cancer cells and adjacent stromal tissues in human pancreatic cancer
}

\author{
TOSHIYUKI ISHIWATA ${ }^{1}$, KAZUMITSU CHO $^{1,2}$, KIYOKO KAWAHARA ${ }^{1}$, TETSUSHI YAMAMOTO ${ }^{1}$, \\ YURI FUJIWARA $^{1}$, EIJI UCHIDA ${ }^{2}$, TAKASHI TAJIRI ${ }^{2}$ and ZENYA NAITO $^{1}$ \\ ${ }^{1}$ Department of Pathology, Integrative Oncological Pathology, Nippon Medical School, 1-1-5 Sendagi, \\ Bunkyo-ku, Tokyo 113-8602; ${ }^{2}$ Surgery for Organ and Biological Regulation (Department of Surgery I), \\ Graduate School of Medicine, Nippon Medical School, 1-1-5 Sendagi, Bunkyo-ku, Tokyo 113-8603, Japan
}

Received February 20, 2007; Accepted April 30, 2007

\begin{abstract}
Lumican is a member of a small leucine-rich proteoglycan family and its overexpression has been reported in carcinoid tumor, breast, colorectal, neuroendocrine cell, uterine cervical and pancreatic cancers. The expression of lumican in stromal tissues in breast cancer is associated with a high tumor grade, a low estrogen receptor expression level and young age. Lumican expression in the cytoplasm in advanced colorectal cancer is correlated with a poor prognosis. Lumican expression was previously reported in pancreatic cancer, but the role of lumican in pancreatic cancer is still not well understood. In this study, we aimed to clarify the role of lumican in pancreatic cancer. Reverse-transcription polymerase chain reaction and Western blot analyses revealed lumican mRNA and protein expression in six pancreatic ductal adenocarcinoma cell lines (i.e. PANC-1, MIA PaCa-2, KLM-1, Capan-1, PK-1 and PK-8). On the basis of its immunoreactivity, lumican was found to be localized in islet cells of normal pancreatic tissues, but not in exocrine cells. In pancreatic cancer tissues, lumican was predominantly localized in the cytoplasm of cancer cells in 30 out of $53(56.6 \%)$ cancer patients, whereas lumican was detected in stromal tissues in 36 out of $53(67.9 \%)$ cancer patients. Lumican expression in pancreatic cancer cells did not correlate with clinicopathological factors, whereas lumican expression in stromal tissues correlated with the female gender, advanced stage, retroperitoneal and duodenal invasion and residual tumor $(\mathrm{p}=0.030,0.038,0.049,0.049$ and 0.048 , respectively). Patients with lumican-positive cancer cells tended to survive longer than those with
\end{abstract}

Correspondence to: Dr Toshiyuki Ishiwata, Department of Pathology, Integrative Oncological Pathology, Nippon Medical School, 1-1-5 Sendagi, Bunkyo-ku, Tokyo 113-8602, Japan

E-mail: ishiwata@nms.ac.jp

Key words: proteoglycan, lumican, pancreatic cancer, immunohistochemistry, reverse-transcription polymerase chain reaction lumican-negative cancer cells $(\mathrm{p}=0.286)$, but patients with lumican-positive stromal tissues had shorter survival than those with lumican-negative stromal tissues $(\mathrm{p}=0.062)$. These results suggest that lumican in stromal tissues plays an important role in the growth and invasion of pancreatic cancer.

\section{Introduction}

Members of the small leucine-rich proteoglycan (SLRP) family have small core proteins of approximately $40 \mathrm{kD}$ and possess 6-10 leucine-rich repeating units flanked by disulfidebonded domains and the presence of chondroitin sulfate or keratan sulfate (1-4). Several studies have demonstrated that SLRP proteins can modulate cellular behavior, including cell migration and proliferation during embryonic development, tissue repair and tumor growth, in addition to their extracellular matrix function as regulators of tissue hydration and collagen fibrillogenesis (5-7). The SLRP family is classified into four groups and class II of the SLRP family consisting of fibromodulin, keratocan, osteomodulin, proline arginine-rich end leucine-rich repeat protein (PRELP) and lumican (8).

Human lumican has 338 amino acids, including a putative 18 -residue signal peptide and its gene is located on chromosome $12 \mathrm{q} 21.3-\mathrm{q} 22$. The lumican core protein contains a central region of leucine-rich repeats flanked on either side by a disulfide-bonded domain and the central region of the molecule possesses four asparagine residues capable of participating in $\mathrm{N}$-linked glycosylation $(9,10)$. Lumican is the major keratan sulfate proteoglycan of the cornea and was reported to colocalize with fibrillar collagen and regulate the assembly and diameter of collagen fibers (4). Lumican is considered a key regulator of collagen fibrillogenesis, a process critical to corneal transparency. Lumican is also distributed in interstitial collagenous matrices in the skin, lungs, intervertebral disks, skeletal muscle, kidneys, intestine, brain, placenta, heart, aorta, liver and pancreas (10-15). Mice that are homozygous for null mutation in lumican show corneal opacification and skin laxity due to inhomogeneous collagen bundles $(16,17)$.

In cancer cell proliferation, most cancer cell types exhibit various grades of fibrosis around cancer nests. Fibrous tissues adjacent to cancer cells mainly consist of collagen fibers and 
fibroblasts and are considered to affect cancer cell proliferation, migration and spread (18). The expression of SLRP family in fibrous tissues around cancer cells was reported in colon and breast cancers (19-21). In colon cancer cells, decorin, a member of the SLRP family, was reported to suppress colonic cancer cell proliferation $(22,23)$. The decorin expression level was reported to be low in human breast cancer tissues, but lumican is overexpressed in the same tissues (20). Furthermore, a high expression level of lumican in breast cancer tissues is associated with a high tumor grade, a low estrogen receptor (ER) expression level and young age (19). Lumican mRNA is expressed specifically in breast cancer tissues, but not in normal breast tissues, suggesting that lumican is differentially expressed during breast tumor progression (19). These findings suggest that lumican in stromal tissues, adjacent to cancer cells play an important role in cancer cell growth.

In colorectal, uterine cervical and pancreatic cancers, we previously reported lumican expression in cancer cells and adjacent stromal tissues $(15,24,25)$. However, little is known about the role of lumican in human pancreatic cancer tissues. Therefore, in this study, we examined the correlations of lumican expression in pancreatic cancer cells with clinicopathological factors and prognosis. Furthermore, we examined the correlations of lumican expression in stromal tissues with clinicopathological factors and prognosis. Here, we report that lumican protein expression in pancreatic cancer cells did not correlate with clinicopathological factors, but stromal lumican expression correlated with the female gender, advanced stage, retroperitoneal and duodenal invasion and residual tumor. Patients with lumican-positive stromal tissues have shorter survival than those with lumican-negative stromal tissues.

\section{Materials and methods}

Materials. The following were purchased: RNeasy minikit from Qiagen GmbH (Hilden, Germany); Takara RNA PCR kit (AMV) Ver. 3.0 from Takara Biotech. (Tokyo, Japan); a goat anti-rabbit IgG-HRP secondary antibody from American Qualex (San Clemente, CA, USA); IPVH membrane and Immobilon western chemiluminescent HRP substrates from Millipore (Yonezawa, Japan); M-PER Mammalian Protein Extraction reagent from Pierce (Rockford, IL, USA); Histofine Simple Stain Max PO (R) kit from Nichirei Biosciences Inc. (Tokyo, Japan); superfrosted slides with a MAS coat from Matsunami Glass Ind., Ltd. (Osaka, Japan); malinol mounting medium from Muto Chemical Co. (Tokyo, Japan); antibiotics and antimycotics from Invitrogen Co. (Carlsbad, CA, USA); Human Tissue Microarray 1 and Human Digestive Tissue Sets from Novagen (Darmstadt, Germany). All other chemicals and reagents were purchased from Sigma Chemical Co. (St. Louis, MO, USA).

Pancreatic cancer cell lines. Pancreatic ductal adenocarcinoma cell lines (PDAC), including PANC-1, MIA PaCa-2, KLM-1, PK-1 and PK-8, were obtained from the Cell Resource Center for Biomedical Research, Institute of Development, Aging and Cancer, Tohoku University (Sendai, Japan). Capan-1 was purchased from American Type Culture Collection (ATCC). The cells were grown in RPMI-1640 medium containing $10 \%$ heat-inactivated fetal bovine serum (FBS), $200 \mathrm{U} / \mathrm{ml}$ penicillin, and $200 \mu \mathrm{g} / \mathrm{ml}$ kanamycin at $37^{\circ} \mathrm{C}$ in a humidified $5 \% \mathrm{CO}_{2}$ atmosphere. Capan-1 was grown in the same medium containing $15 \%$ FBS.

Pancreatic cancer tissues. Tissues from 53 patients with invasive PDAC were obtained for this study. These patients received treatment at Nippon Medical School Hospital (Bunkyo-ku, Tokyo, Japan) from 1995 to 2003. None of the patients received preoperative chemotherapy and radiotherapy. The patients consisted of 36 males and 17 females, whose median age was 64 years (range, 35-84 years). The clinicopathologic stage was determined according to the TNM classification system of the International Union Against Cancer (UICC) and additionally characterized on the basis of the Japanese Pancreas Society classification (Table I). The median follow-up period was 14.1 months. Paraffinembedded specimens were prepared for immunohistochemistry as previously described $(26,27)$. This study was carried out in accordance with the principles embodied in the Declaration of Helsinki, 1975 and the informed consent for the usage of pancreatic tissues was obtained from each patient. Normal pancreatic tissues were obtained from Human Digestive Tissue Sets and Human Tissue Microarray 1.

Reverse-transcription polymerase chain reaction ( $R T-P C R)$. Total RNA was extracted from pancreatic cancer cell lines using the RNeasy minikit according to the manufacturer's instructions. Then, cDNA synthesis and PCR were performed using the Takara RNA PCR kit. The primer pair used for lumican corresponded to nucleotides (nts) 659-678 (5'-TGATCT-GCA-GTG-GCT-CAT-TC-3') and nts 1042-1064 (5'GAA-ATA-CTC-ATC-AGG-GAT-GTT-GC-3') (406 bp, accession No.NM_002345). B-actin mRNA, as the positive control, was amplified using the following primer pairs: nts 254-273 (5'-AAG-AGA-GGC-ATC-CTC-ACC-CT-3') and nts 452-471 (5'-TAC-ATG-GCT-GGG-GTG-TTG-AA-3') (218 bp, accession No. NM_001101). PCR was carried out in a Takara PCR thermal cycler MP (Takara, Tokyo, Japan) for $2 \mathrm{~min}$ at $94^{\circ} \mathrm{C}$, followed by 35 cycles, each consisting of $30 \mathrm{sec}$ at $94^{\circ} \mathrm{C}, 30 \mathrm{sec}$ at $60^{\circ} \mathrm{C}$ and $1 \mathrm{~min}$ at $72^{\circ} \mathrm{C}$. The authenticity of the PCR product was confirmed by the direct sequence method. Total RNA not subjected to reverse transcription was used as the negative control.

Western blot analysis. Protein extraction was performed in accordance with the protocol for the use of the M-Per Mammalian Protein Extraction reagent. Briefly, cultured pancreatic cancer cells were solubilized in the M-Per reagent with Protease Inhibitor Cocktail. Lysates were centrifuged for $10 \mathrm{~min}$ at 13,000 rpm to pellet cell debris. The resulting supernatants were collected and protein concentration was measured by the Bradford method. The cleared protein lysates were subjected to sodium dodecyl sulfate-polyacrylamide gel electrophoresis (SDS-PAGE) under reducing conditions and the separated proteins were transferred to Immobilon P transfer membranes. The membranes were immersed in 5\% skim milk in Tris-buffered saline containing $0.05 \%$ Tween-20 (TBS-T) for $60 \mathrm{~min}$ at room temperature (RT), then incubated for $16 \mathrm{~h}$ at $4{ }^{\circ} \mathrm{C}$ with an anti-lumican antibody (dilution, 1:800). The 


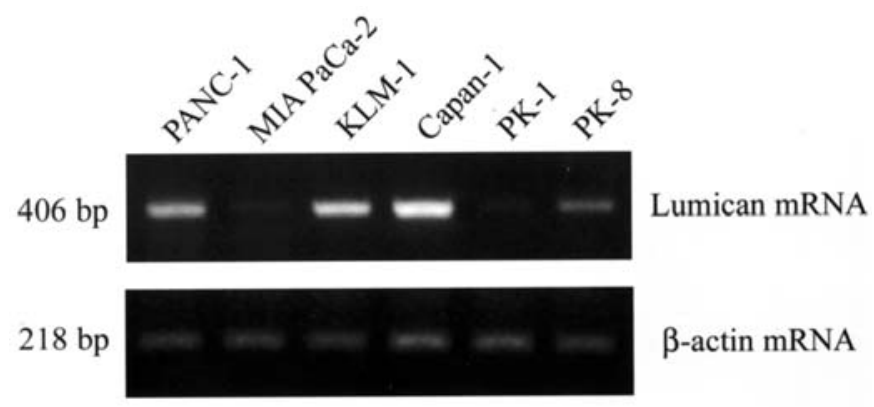

Figure 1. RT-PCR analysis of lumican mRNA in PDAC cell lines. Total RNA was extracted from PANC-1, MIA PaCa-2, KLM-1, Capan-1, PK-1 and PK-8 cells and then cDNA synthesis and PCR were performed. Lumican and $\beta$-actin mRNAs were detected as bands of 406 and $218 \mathrm{bp}$ (upper and lower panels, respectively).

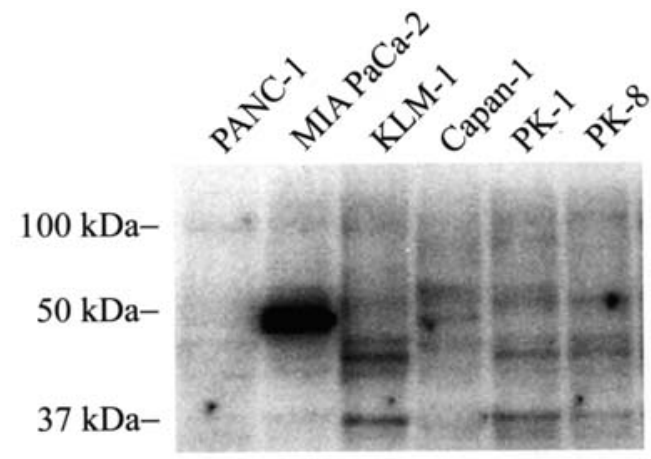

Figure 2. Western blot analysis of lumican in PDAC cell lines. In six PDAC cell lines, 37- to 100-kD lumican protein fragments are detected.

anti-lumican antibody used in this study was an affinitypurified rabbit polyclonal antibody raised against a peptide corresponding to amino acids of human lumican (13). The membranes were washed and incubated with the HRPconjugated anti-rabbit IgG antibody (dilution,1: 4000) for $60 \mathrm{~min}$. After washing, the blots were visualized using enhanced chemiluminescence and detected with a ChemiDoc XRS system (Bio-Rad Laboratories, Inc., Hercules, CA, USA). To confirm the almost equal loadings of the proteins, the membranes were washed and reprobed with an anti- $\beta$-actin antibody.

Immunohistochemistry. Paraffin-embedded tissue sections $(3.5 \mu \mathrm{m})$ were immunostained using the Histofine Simple Stain Max PO (R) kit. After deparaffinization, endogenous peroxidase activity was blocked by incubation with $0.3 \%$ hydrogen peroxide in methanol for $30 \mathrm{~min}$ and the sections were incubated with the anti-lumican antibody for $20 \mathrm{~h}$ at $4^{\circ} \mathrm{C}$ (dilution, 1:500) using PBS containing 1\% bovine serum albumin (BSA). The anti-lumican antibody used was the same antibody employed in Western blot analysis. Bound antibodies were detected with Simple Stain Max PO $(\mathrm{R})$ reagents using diaminobenzidine-tetrahydrochloride (DAB) as the substrate, and the sections were counterstained with Mayer's hematoxylin. Negative control studies were performed by omitting the primary antibodies. The immunohistochemical results for lumican in cancer cells were evaluated as follows:

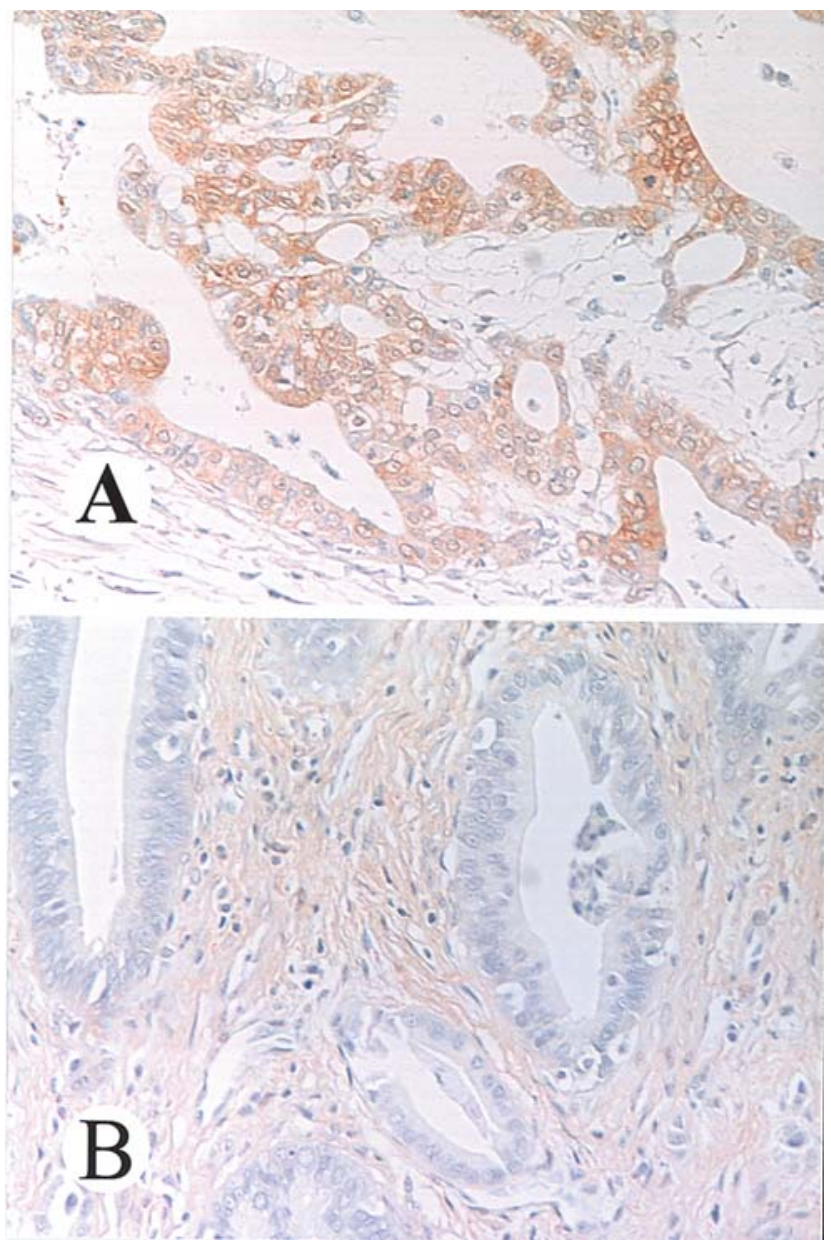

Figure 3. Characteristic staining pattern of lumican in PDAC tissues. In some patients, lumican is strongly expressed in the cytoplasm of PDAC cells, but not in adjacent stromal tissues (A). Lumican is predominantly localized in stromal tissues adjacent to cancer cells, but not in the cytoplasm of cancer cells (B). A, B: immunohistochemistry. Original magnification: A, B; X200.

when staining was noted in the cytoplasm of more than $30 \%$ of tumor cells, regardless of the intensity of staining, the cells were designated as lumican-positive. The immunohistochemical results for stromal tissues, which are adjacent to cancer cells, were also evaluated as positive or negative for lumican. Two investigators (T.I. and K.C.) separately evaluated all the specimens in a blinded manner.

\section{Results}

RT-PCR analysis of lumican mRNA in PDAC cell lines. To examine the expression of lumican mRNA in human cultured PDAC cell lines, RT-PCR analysis was performed. Lumican mRNA and $B$-actin mRNA, which were observed as bands of 406 bp and 218 bp, respectively, were detected in PANC-1, MIA PaCa-2, KLM-1, Capan-1, PK-1 and PK-8 cells (Fig. 1, upper and lower panels, respectively).

Western blot analysis of lumican in PDAC cell lines. To characterize lumican in PDAC cells, total protein was extracted from PANC-1, MIA PaCa-2, KLM-1, Capan-1, PK-1 and PK-8 pancreatic cancer cells. Western blot analysis 
Table I. Correlation of clinicopathological factors with lumican expression in pancreatic cancer.

\begin{tabular}{|c|c|c|c|}
\hline \multirow[b]{2}{*}{ Variable } & \multicolumn{2}{|c|}{ Lumican expression } & \multirow[b]{2}{*}{$\mathrm{P}$} \\
\hline & $\begin{array}{c}\text { Negative } \\
(\mathrm{n}=23 / 53,43.4 \%)\end{array}$ & $\begin{array}{c}\text { Positive } \\
(\mathrm{n}=30 / 53,56.6 \%)\end{array}$ & \\
\hline Gender & & & 0.823 \\
\hline Male & 16 & 20 & \\
\hline Female & 7 & 10 & \\
\hline $\begin{array}{l}\text { Age mean } \pm \mathrm{SD} \\
\text { (range) }\end{array}$ & $\begin{array}{c}60.6 \pm 12.1 \\
(35-78)\end{array}$ & $\begin{array}{c}66.5 \pm 9.8 \\
(50-84)\end{array}$ & 0.058 \\
\hline \multicolumn{3}{|l|}{ UICC classification } & \\
\hline $\mathrm{T}$ - primary tumor & & & 0.765 \\
\hline 1 & 1 & 2 & \\
\hline 2 & 1 & 2 & \\
\hline 3 & 8 & 7 & \\
\hline 4 & 13 & 19 & \\
\hline \multicolumn{3}{|l|}{$\mathrm{N}$ - Regional lymph nodes } & 0.472 \\
\hline 0 & 7 & 12 & \\
\hline 1 & 16 & 18 & \\
\hline \multicolumn{3}{|l|}{ M - Distant metastasis } & 0.848 \\
\hline 0 & 22 & 29 & \\
\hline 1 & 1 & 1 & \\
\hline \multicolumn{3}{|l|}{ G - Histological grading } & 0.491 \\
\hline 1 & 12 & 19 & \\
\hline 2 & 11 & 10 & \\
\hline 3 & 0 & 1 & \\
\hline 4 & 0 & 0 & \\
\hline Stage & & & 0.643 \\
\hline I or II & 5 & 5 & \\
\hline III or IV & 18 & 25 & \\
\hline \multicolumn{4}{|l|}{ Other tumor characteristics } \\
\hline Lymphatic invasion & & & 0.872 \\
\hline Negative & 2 & 3 & \\
\hline Positive & 21 & 27 & \\
\hline Venous invasion & & & 0.635 \\
\hline Negative & 16 & 19 & \\
\hline Positive & 7 & 11 & \\
\hline $\begin{array}{l}\text { Nerve invasion } \\
\text { (intrapancreatic) }\end{array}$ & & & 0.402 \\
\hline Negative & 6 & 5 & \\
\hline Positive & 17 & 25 & \\
\hline
\end{tabular}

of the proteins from these cells using an anti-lumican antibody showed that lumican was expressed in these cancer cells (Fig. 2). Several forms of lumican were reported to be localized in human tissues, which differ in the type of their glycosylated chains whose sizes range from $\sim 37$ to $100 \mathrm{kDa}$ $(15,24)$.

Immunohistochemistry of lumican in pancreatic cancer tissues. To confirm the localization of the lumican protein in
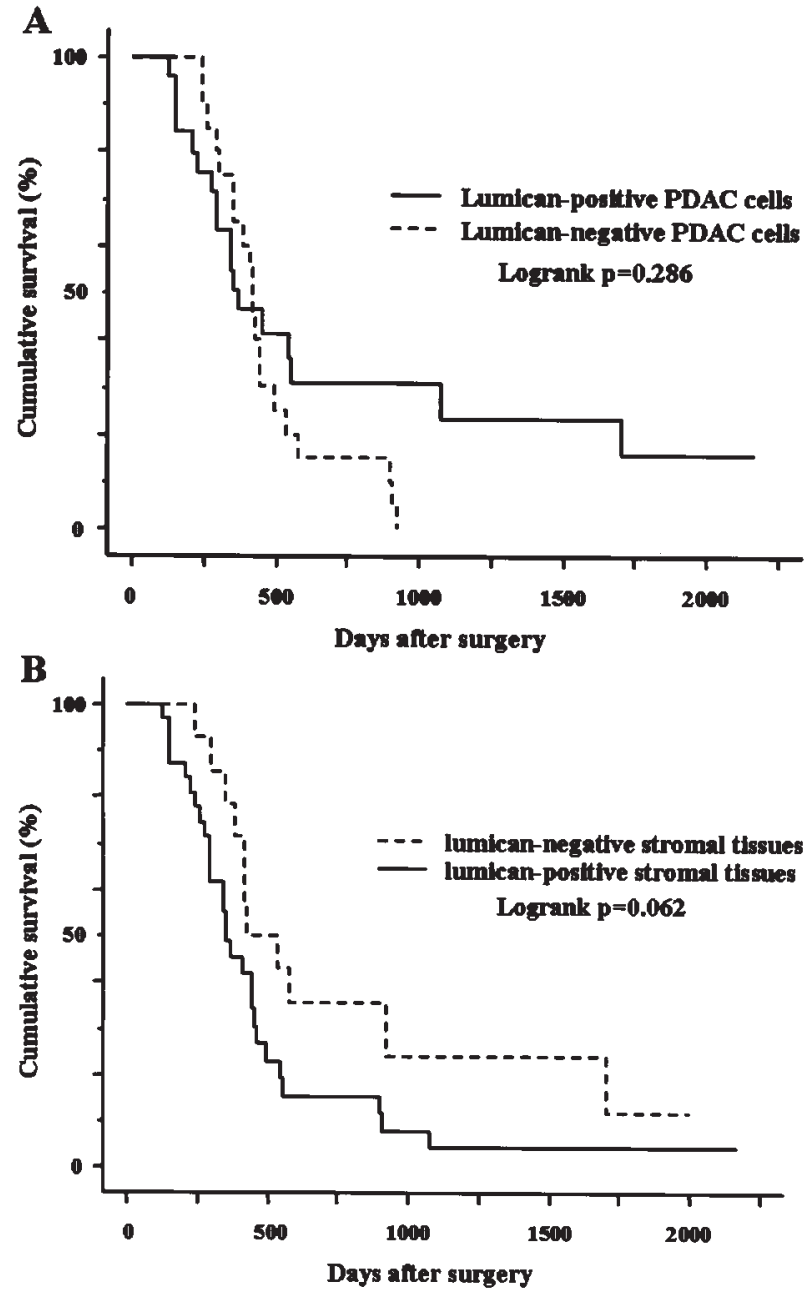

Figure 4. Curves for all patients with lumican-positive or lumican-negative cytoplasm of PDAC cells $(\mathrm{A}, \mathrm{p}=0.286)$. Curves for all patients with lumican-positive or lumican-negative stromal tissues adjacent to PDAC cells $(B, p=0.062)$.

human pancreatic cancer tissues, immunohistochemical analysis was performed. In normal pancreatic tissues, lumican was detected in alpha cells of islets, as previously reported (15). Lumican was localized in pancreatic cancer cells and adjacent stromal tissues. Lumican was expressed in the cytoplasm of pancreatic cancer cells in 30 out of 53 cancer patients (Fig. 3A, 56.6\%). On the other hand, lumican was localized in stromal tissues, which is adjacent to cancer cells, in 36 out of 53 cancer patients (Fig. 3B, 67.9\%).

Correlation of lumican expression in cancer cells or stromal tissues with clinicopathological factors. Lumican expression in pancreatic cancer cells did not correlate with any clinicopathological factors (Table I), whereas that in stromal tissues significantly correlate with the female gender, advanced stage, retroperitoneal and duodenal invasion and residual tumor (Table II).

Survival of patients with lumican-positive or lumican-negative pancreatic cancer cells and stromal tissues. Lumican expression in pancreatic cancer cells tended to correlate with 
Table II. Correlation of clinicopathological factors with stromal lumican expression in pancreatic cancer.

\begin{tabular}{|c|c|c|c|}
\hline \multirow[b]{2}{*}{ Variable } & \multicolumn{2}{|c|}{ Stromal lumican expression } & \multirow[b]{2}{*}{$\mathrm{P}$} \\
\hline & $\begin{array}{c}\text { Negative } \\
(\mathrm{n}=17 / 53,32.1 \%)\end{array}$ & $\begin{array}{c}\text { Positive } \\
(\mathrm{n}=36 / 53,67.9 \%)\end{array}$ & \\
\hline Gender & & & 0.030 \\
\hline Male & 15 & 21 & \\
\hline Female & 2 & 15 & \\
\hline $\begin{array}{l}\text { Age mean + SD } \\
\text { (range) }\end{array}$ & $\begin{array}{c}61.2 \pm 9.6 \\
(45-78)\end{array}$ & $\begin{array}{c}65.1 \pm 11.7 \\
(35-84)\end{array}$ & 0.222 \\
\hline \multicolumn{4}{|l|}{ UICC classification } \\
\hline $\mathrm{T}$ - primary tumor & & & 0.068 \\
\hline 1 & 0 & 3 & \\
\hline 2 & 3 & 0 & \\
\hline 3 & 7 & 8 & \\
\hline 4 & 7 & 25 & \\
\hline \multicolumn{3}{|l|}{$\mathrm{N}$ - Regional lymph nodes } & 0.242 \\
\hline 0 & 8 & 11 & \\
\hline 1 & 9 & 25 & \\
\hline \multicolumn{3}{|l|}{ M - Distant metastasis } & 0.322 \\
\hline 0 & 17 & 34 & \\
\hline 1 & 0 & 2 & \\
\hline \multicolumn{3}{|l|}{ G - Histological grading } & 0.912 \\
\hline 1 & 10 & 21 & \\
\hline 2 & 7 & 14 & \\
\hline 3 & 0 & 1 & \\
\hline 4 & 0 & 0 & \\
\hline \multicolumn{3}{|l|}{ Stage } & 0.038 \\
\hline I or II & 6 & 4 & \\
\hline III or IV & 11 & 32 & \\
\hline \multicolumn{4}{|c|}{ Other tumor characteristics } \\
\hline \multicolumn{3}{|c|}{ Retroperitoneal invasion: RP } & 0.049 \\
\hline Negative & 10 & 8 & \\
\hline Positive & 7 & 28 & \\
\hline \multicolumn{3}{|l|}{ Duodenal invasion: DU } & 0.049 \\
\hline Negative & 12 & 15 & \\
\hline Positive & 5 & 21 & \\
\hline \multicolumn{3}{|l|}{ Residual tumor: $\mathrm{R}$} & 0.048 \\
\hline 0 & 11 & 13 & \\
\hline 1 & 6 & 22 & \\
\hline 2 & 0 & 1 & \\
\hline
\end{tabular}

longer survival (Fig. 4A, p=0.286). In contrast, lumican expression in stromal tissues tended to correlate with shorter survival (Fig. 4B, p=0.061).

\section{Discussion}

We previously reported lumican expression in MIA PaCa-2 and PK-8 cells (15). In addition to the cancer cell lines, four PDAC cells also expressed lumican mRNA and protein.
Different molecular weights of lumican in the cancer cell lines were detected, indicating that pancreatic cancer possesses many types of glycosylated side chain, as previously described (15). Five colorectal cancer cell lines and three uterine cervical cancer cell lines were also reported to express lumican mRNA and protein $(24,25)$. These cancer cell lines express lumican, but their original cells, including pancreatic duct cells, colorectal epithelial cells and uterine cervical epithelial cells, do not express lumican. A recent study has shown that lumican is expressed and secreted by melanoma cell lines, but not by normal melanocytes (28). The role of newly synthesized lumican in cancer cell lines is still not clearly elucidated. Lumican-transfected B16F1 mouse melanoma cells are characterized by a strong suppression of their anchorageindependent proliferation and capacity to invade the extracellular matrix gel in vitro (29). After subcutaneous injections of transfected B16F1 cells to syngenic mice, lumican expression significantly suppresses subcutaneous tumor formation in vivo, with a concomitant decrease in cyclin D1 expression level. Moreover, lumican induces or enhances the apoptosis of B16F1 cells. Our previous report showed that a decreased expression level of lumican in HEK 293 cells induces the growth of the cells (30). Neuroendocrine tumors possess numerous neuroendocrine granules and are classified into carcinoid tumors and neuroendocrine carcinoma (NEC) (31-33). Carcinoid tumors are slow-growing and not highly metastatic, whereas NECs are aggressive, easily metastasize to distant organs and have a poor prognosis. The lumican expression level was higher in the cytoplasm of carcinoid tumors than in that of NECs, but the expression level of lumican in stromal tissues was not significantly different from that in the stromal tissues of NECs (34). Lumican expression in the cytoplasm of pancreatic cancer cells was detected in $56.6 \%$ of cancer patients and it did not correlate with clinicopathological factors, including tumor size and local and distant metastases. Furthermore, patients with lumican expressed in pancreatic cancer cells tended to survive longer. These lines of evidence suggest that the ectopic expression or overexpression of lumican in epithelial cells, including cancer cells does not correlate with aggressive cell growth or plays a role in growth inhibition.

In breast cancer tissues, lumican mRNA is overexpressed in fibroblasts adjacent to cancer cells, but not in cancer cells $(19,20)$. An enhanced lumican deposition was observed in the collagenous stroma of tumors, particularly at the margins of invasive tumors. A high expression level of stromal lumican is associated with a high pathological tumor grade, a low estrogen receptor level in cancer tissues and young age (19). On the other hand, a high expression level of lumican in breast cancer was reported to be associated with a slow progression and a better prognosis (35). In this study, lumican expression in stromal tissues correlated with the female gender, advanced stage, retroperitoneal and duodenal invasion and residual tumor and tended to correlate with a poor prognosis. Fibrosis of various degrees is observed in stromal tissues close to cancer cells. Collagen fibers are the main component of fibrosis and lumican was reported to regulate the assembly and diameter of collagen fibers (4). A recent study showed that SLRPs, including lumican interacting at the surface of either type I or type II collagen fibrils, can decrease the susceptibility 
of collagen fibers to both MMP-1 and MMP-13 cleavage (36). Lumican in stromal tissues, adjacent to cancer cells may modulate the characteristics of collagen fibers and induce the invasion activity of pancreatic cancer cells.

In pancreatic cancer, the lumican expression level in stromal tissues was significantly higher in female patients. In breast cancer tissues, a higher expression level of lumican in stromal tissue correlated with a lower ER expression level in cancer cells (19). During pregnancy, ER mRNA and lumican mRNA expression levels in the cartilage are significantly high in multiparous rabbits compared with those in the control cartilage (37). ER mRNA expression level does not change during pregnancy in primigraveda rabbits, whereas lumican mRNA expression level decreases. These findings may indicate the correlation between lumican expression in stromal tissues and female hormones. To elucidate the relationship between lumican and estrogen or progesterone, further study of female-hormone-related cancer cells, including breast cancer and endometrial cancer cells is required.

In summary, lumican expression in stromal tissues correlated with the female gender, advanced stage, retroperitoneal and duodenal invasion and residual tumor in pancreatic cancer. Furthermore, stromal lumican expression in pancreatic cancer tended to correlate with a shorter survival. These results suggest that lumican in stromal tissues plays an important role in pancreatic cancer cell growth and invasion.

\section{Acknowledgements}

We thank Ms. Taeko Suzuki, Ms. Yoko Kawamoto, Mr. Kiyoshi Teduka and Mr. Takenori Fujii for their excellent technical assistance. We also thank Ms. Yuko Ono for preparing the manuscript. This study was supported by a Grant-in-Aid for Scientific Research (C, No. 90203041 for T.I. and C, No. 20237184 for Z.N.) from the Japanese Society for the Promotion of Science.

\section{References}

1. Krusius T and Ruoslahti E: Primary structure of an extracellular matrix proteoglycan core protein deduced from cloned cDNA. Proc Natl Acad Sci USA 83: 7683-7687, 1986.

2. Fisher LW, Termine JD and Young MF: Deduced protein sequence of bone small proteoglycan I (biglycan) shows homology with proteoglycan II (decorin) and several nonconnective tissue proteins in a variety of species. J Biol Chem 264: 4571-4576, 1989.

3. Oldberg A, Antonsson P, Lindblom K and Heinegard D: A collagen-binding $59 \mathrm{kd}$ protein (fibromodulin) is structurally related to the small interstitial proteoglycans PG-S1 and PG-S2 (decorin). EMBO J 8: 2601-2604, 1989.

4. Blochberger TC, Vergnes JP, Hempel J and Hassell JR: cDNA to chick lumican (corneal keratan sulfate proteoglycan) reveals homology to the small interstitial proteoglycan gene family and expression in muscle and intestine. J Biol Chem 267: 347-352, 1992.

5. Iozzo RV: The family of the small leucine-rich proteoglycans: key regulators of matrix assembly and cellular growth. Crit Rev Biochem Mol Biol 32: 141-174, 1997.

6. Fullwood NJ, Davies Y, Nieduszynski IA, Marcyniuk B, Ridgway AE and Quantock AJ: Cell surface-associated keratan sulfate on normal and migrating corneal endothelium. Invest Ophthalmol Vis Sci 37: 1256-1270, 1996.

7. Wight TN, Kinsella MG and Qwarnstrom EE: The role of proteoglycans in cell adhesion, migration and proliferation. Curr Opin Cell Biol 4: 793-801, 1992.
8. Matsushima N, Ohyanagi T, Tanaka T and Kretsinger RH: Supermotifs and evolution of tandem leucine-rich repeats within the small proteoglycans - biglycan, decorin, lumican, fibromodulin, PRELP, keratocan, osteoadherin, epiphycan and osteoglycin. Proteins 38: 210-225, 2000.

9. Chakravarti S, Stallings RL, SundarRaj N, Cornuet PK and Hassell JR: Primary structure of human lumican (keratan sulfate proteoglycan) and localization of the gene (LUM) to chromosome 12q21.3-q22. Genomics 27: 481-488, 1995.

10. Grover J, Chen XN, Korenberg JR and Roughley PJ: The human lumican gene. Organization, chromosomal location and expression in articular cartilage. J Biol Chem 270: 21942-21949, 1995.

11. Ying S, Shiraishi A, Kao CW, et al: Characterization and expression of the mouse lumican gene. J Biol Chem 272: 30306-30313, 1997.

12. Sztrolovics R, Alini M, Mort JS and Roughley PJ: Age-related changes in fibromodulin and lumican in human intervertebral discs. Spine 24: 1765-1771, 1999.

13. Baba H, Ishiwata T, Takashi E, Xu G and Asano G: Expression and localization of lumican in the ischemic and reperfused rat heart. Jpn Circ J 65: 445-450, 2001.

14. Qin H, Ishiwata T and Asano G: Effects of the extracellular matrix on lumican expression in rat aortic smooth muscle cells in vitro. J Pathol 195: 604-608, 2001.

15. Ping Lu Y, Ishiwata T and Asano G: Lumican expression in alpha cells of islets in pancreas and pancreatic cancer cells. J Pathol 196: 324-330, 2002.

16. Chakravarti S, Magnuson T, Lass JH, Jepsen KJ, LaMantia C and Carroll $\mathrm{H}$ : Lumican regulates collagen fibril assembly: skin fragility and corneal opacity in the absence of lumican. J Cell Biol 141: 1277-1286, 1998

17. Chakravarti S, Petroll WM, Hassell JR, et al: Corneal opacity in lumican-null mice: defects in collagen fibril structure and packing in the posterior stroma. Invest Ophthalmol Vis Sci 41: 3365-3373, 2000 .

18. Hardingham TE and Fosang AJ: Proteoglycans: many forms and many functions. FASEB J 6: 861-870, 1992.

19. Leygue E, Snell L, Dotzlaw H, et al: Expression of lumican in human breast carcinoma. Cancer Res 58: 1348-1352, 1998.

20. Leygue E, Snell L, Dotzlaw H, et al: Lumican and decorin are differentially expressed in human breast carcinoma. J Pathol 192: 313-320, 2000.

21. Adany R, Heimer R, Caterson B, Sorrell JM and Iozzo RV: Altered expression of chondroitin sulfate proteoglycan in the stroma of human colon carcinoma. Hypomethylation of PG-40 gene correlates with increased PG-40 content and mRNA levels. J Biol Chem 265: 11389-11396, 1990.

22. Reed CC, Gauldie J and Iozzo RV: Suppression of tumorigenicity by adenovirus-mediated gene transfer of decorin. Oncogene 21 : 3688-3695, 2002.

23. Santra M, Skorski T, Calabretta B, Lattime EC and Iozzo RV: De novo decorin gene expression suppresses the malignant phenotype in human colon cancer cells. Proc Natl Acad Sci USA 92: 7016-7020, 1995.

24. Lu YP, Ishiwata T, Kawahara K, et al: Expression of lumican in human colorectal cancer cells. Pathol Int 52: 519-526, 2002.

25. Naito Z, Ishiwata T, Kurban G, et al: Expression and accumulation of lumican protein in uterine cervical cancer cells at the periphery of cancer nests. Int J Oncol 20: 943-948, 2002.

26. Ishiwata T, Friess H, Buchler MW, Lopez ME and Korc M: Characterization of keratinocyte growth factor and receptor expression in human pancreatic cancer. Am J Pathol 153: 213-222, 1998.

27. Ishiwata T: Immunohistochemical and in situ hybridization analysis of lumican in colorectal carcinoma, In: Handbook of immunohistochemistry and in situ hybridization of human carcinomas. M.A. Hayat (ed.) Elsevier Academic Press., Burlington, pp237-243, 2004.

28. Sifaki M, Assouti M, Nikitovic D, Krasagakis K, Karamanos NK and Tzanakakis GN: Lumican, a small leucine-rich proteoglycan substituted with keratan sulfate chains is expressed and secreted by human melanoma cells and not normal melanocytes. IUBMB Life 58: 606-610, 2006.

29. Vuillermoz B, Khoruzhenko A, D'Onofrio MF, et al: The small leucine-rich proteoglycan lumican inhibits melanoma progression. Exp Cell Res 296: 294-306, 2004.

30. Ishiwata T, Fujii T, Ishiwata S, Ikegawa S and Naito Z: Effect of morpholino antisense oligonucleotide against lumican mRNA in human embryonic kidney (HEK) 293 cells. Pathol Int 54: 77-81, 2004. 
31. Caplin ME, Buscombe JR, Hilson AJ, Jones AL, Watkinson AF and Burroughs AK: Carcinoid tumor. Lancet 352: 799-805, 1998.

32. Kulke MH and Mayer RJ: Carcinoid tumors. N Engl J Med 340: 858-868, 1999

33. Bernick PE, Klimstra DS, Shia J, et al: Neuroendocrine carcinomas of the colon and rectum. Dis Colon Rectum 47: 163-169, 2004.

34. Shinji S, Tajiri T, Ishiwata T, Seya T, Tanaka N and Naito Z: Different expression levels of lumican in human carcinoid tumor and neuroendocrine cell carcinoma. Int J Oncol 26: 873-880, 2005.
35. Troup S, Njue C, Kliewer EV, et al: Reduced expression of the small leucine-rich proteoglycans, lumican and decorin is associated with poor outcome in node-negative invasive breast cancer. Clin Cancer Res 9: 207-214, 2003.

36. Geng Y, McQuillan D and Roughley PJ: SLRP interaction can protect collagen fibrils from cleavage by collagenases. Matrix Biol 25: 484-491, 2006.

37. Hellio LE, Graverand MP, Reno C and Hart DA: Influence of pregnancy on gene expression in rabbit articular cartilage. Osteoarthritis Cartilage 6: 341-350, 1998. 